\title{
Статус пигментного аппарата травянистых многолетников из коллекции ботанического сада Сургутского государственного университета
}

\section{The status of the pigment apparatus of herbaceous perennials from the collection of the Botanical Garden of Surgut state university}

\author{
Турбина И. Н., Филимонова М. В. \\ Turbina I. N., Filimonova M. V. \\ Сургутский государственный университет, г.Сургут, Россия.E-mail: scilla3@yandex.ru; felis75@mail.ru \\ Surgut State University, Surgut, Russia
}

\begin{abstract}
Peфераm. Для изучения механизмов адаптации растений в условиях культуры были проведены биохимические исследования листьев семи видов травянистых многолетников, раннее полученных из Центрального сибирского ботанического сада СО РАН (г. Новосибирск). Отмечено, что наблюдается видовая специфичность по содержанию фотосинтетических пигментов, так, повышенным содержанием хлорофилла характеризовались виды семейства Asteraceae. Соотношение хлорофиллы/каротиноиды достоверно отличалось у растений разных фаз развития и видов. Максимальное значение соотношения хлорофиллы/каротиноиды отмечено у Helenium hoopesi$i a$, что связанно с его биологической особенностью и Achillea filipendulina, Centaurea dealbata в период образования генеративных органов и цветения. В целом пигментный состав листьев интродуцентов свидетельствует об их относительно высоком физиологическом статусе.
\end{abstract}

Ключевые слова. Ботанический сад, интродукция растений, каротиноиды, пигменты фотосинтеза, хлорофиллы.

Summary. The biochemical studies of the leaves of seven species of herbaceous perennials previously obtained from the Central Siberian Botanical Garden, (Siberian Branch of Russian Academy of Sciences, Novosibirsk) to examine the adaptation mechanisms of plants in culture were carried out. It has been shown that the species specificity of photosynthetic pigments content was observed. Thus the higher content of chlorophyll in plants species of Asteraceae family was found. The ratio of chlorophyll/carotenoids was significantly different in plants of varied developmental phases and species. The maximum value of the chlorophyll/carotenoids ratio was observed in Helenium hoopesiia, which is related to its biological peculiarity. The species Achillea filipendulina and Centaurea dealbata had a high index of this ratio during the period of formation of the generative organs and flowering. In general, the photosynthetic pigments composition of the introduced species leaves indicates their relatively high physiological status.

Key words. Botanical garden, carotenoids, chlorophylls, photosynthesis pigments, plant introduction.

В условиях резкого континентального климата Сибири изучение декоративных травянистых растений остается по-прежнему актуальным. В задачи Ботанического сада Сургутского государственного университета (СурГУ) входят работы по созданию специальных коллекций живых растений, развитие фундаментальных и прикладных исследований с целью сохранения, изучения и обогащения генофонда растений природной и культурной флоры, а также для его наиболее эффективного научного, культурного и хозяйственного изучения.

Результаты интродукционных исследований также служат основой для озеленения. Озеленение городов играет важную роль в организации благоприятной среды для жизни человека. В создании привлекательных зеленых насаждений большую ценность представляют холодостойкие многолетние растения с ранним цветением и длительным периодом вегетации.

В настоящее время коллекция декоративных растений Ботанического сада насчитывает более 100 видов и сортов травянистых растений, относящимся к 35 родам и 17 семействам местной и инорайонной флоры. Важными защитно-приспособительными реакциями растений к условиям среды яв- 
ляются количественные и качественные изменения пигментного аппарата листа. Данные параметры чувствительны к изменениям окружающей среды, поэтому могут быть использованы в ранней диагностике состояния растительного организма (Ананьина, 2003). Таким образом, уровень накопления фотосинтетических пигментов является неспецифическим биохимическим показателем степени адаптации растений к экологическим условиям (Карпова, Фершалова, 2016).

Целью исследования являлось изучение статуса комплекса фотосинтетических пигментов травянистых растений в условиях интродукции.

\section{Материалы и методики исследования}

Объектом исследования служили семь видов травянистых многолетников: сем. Asteraceae - тысячелистник таволговый (Achillea filipendulina Lam.), василек подбеленный (Centaurea dealbata Willd.), дендрантема завадского (Dendranthema zawadskii (Herbich) Tzvel), гелениум Хупа (Helenium hoopesiia. Gray); сем. Hemerocallidoideae - лилейник рыжий (Hemerocallis fulva L.), лилейник малый (Hетеrocallis minor Mill.); сем. Scrophulariaceae - пенстемон наперстянковый (Penstemon digitalis Nutt. ex Sims), ранее интродуцированные в условиях лесостепной зоны Западной Сибири (Фомина, 2012). Посадочный материал был получен весной 2018 г. из Центрального сибирского ботанического сада. Все растения были высажены на открытом участке, с единым агротехническим фоном. Содержание пигментов фотосинтеза - хлорофилла $a$ (хл $a)$, хлорофилла $b$ (хл $b)$, каротиноидов $($ С $)$ и соотношение хлорофилл $a /$ хлорофилл $b$ и хлорофилла $a+b /$ каротиноиды - является одним из биохимических показателей степени адаптации растений к экологическим условиям (Lichtenthaler, Buschmann, 2001.) Исследования пигментного фонда декоративных растений проводились совместно с Центром коллективного пользования СурГУ и Научно-образовательным центром Института естественных и технических наук. Содержание фотосинтетических пигментов определяли в трехкратной биологической повторности на спектрофотометре СФ-56 по методике Е. В. Барковского (2013). Наличие пигментов фотосинтеза рассчитывали в мг/г сухого вещества. Статистическая обработка полученных данных и построение графиков выполнены в программе Excel 2007 for Windows.

\section{Результаты и их обсуждение}

Исследования концентрации фотосинтетических пигментов в листьях интродуцированных растений проводили в осенний период, так как содержание хлорофиллов $a$ и $b$ в листьях и отношение их суммы к содержанию каротиноидов являются надежными показателями физиологического состояния растений и индикаторами стресса. Анализ полученных данных выявил широкое варьирование значения суммы хлорофиллов $a$ и $b$ от 3,6 до 7,6 мг/г и каротиноидов от 0,73 до 1,12 мг/г (табл.). Среди исследованных нами видов повышенным содержанием хлорофилла характеризовались виды семейства Asteraceae, у которых суммарное содержание хлорофилла в 1,5-2 раза выше по сравнению с видами семейства Hemerocallidoideae. В накоплении каротиноидов данной закономерности не наблюдается.

Соотношение хлорофилл $a /$ хлорофилл $b$ для всех опытных растений находится в небольшом интервале от 2,6 до 3,8 мг/г, что говорит о благоприятных условиях произрастания и стабильном режиме освещенности (рис.).

Таблица

Содержание фотосинтетических пигментов в листьях травянистых растений из коллекции ботанического сада СурГУ, мг/г.

\begin{tabular}{|c|l|c|c|c|c|}
\hline № & \multicolumn{1}{|c|}{ Вид } & Хл $a$ & Хл $b$ & Хл $(a+b)$ & Ск \\
\hline 1 & Achillea filipendulina & $5,74 \pm \_0,014$ & $1,86 \pm 0,009$ & $7,60 \pm 0,007$ & $0,94 \pm 0,005$ \\
\hline 2 & Centaurea dealbata & $4,95 \pm 0,004$ & $1,61 \pm 0,009$ & $6,56 \pm 0,006$ & $0,86 \pm 0,004$ \\
\hline 3 & Dendranthema zawadskii & $4,14 \pm 0,007$ & $1,36 \pm 0,011$ & $5,49 \pm 0,004$ & $0,85 \pm 0,007$ \\
\hline 4 & Helenium hoopesiia & $4,36 \pm 0,008$ & $1,69 \pm 0,009$ & $6,06 \pm 0,003$ & $0,73 \pm 0,004$ \\
\hline 5 & Hemerocallis fulva & $2,84 \pm 0,002$ & $0,74 \pm 0,006$ & $3,57 \pm 0,003$ & $0,77 \pm 0,003$ \\
\hline 6 & Hemerocallis minor & $3,65 \pm 0,006$ & $1,08 \pm 0,004$ & $4,73 \pm 0,002$ & $1,12 \pm 0,004$ \\
\hline 7 & Penstemon digitalis & $3,78 \pm 0,004$ & $1,41 \pm 0,007$ & $5,19 \pm 0,005$ & $0,94 \pm 0,004$ \\
\hline
\end{tabular}




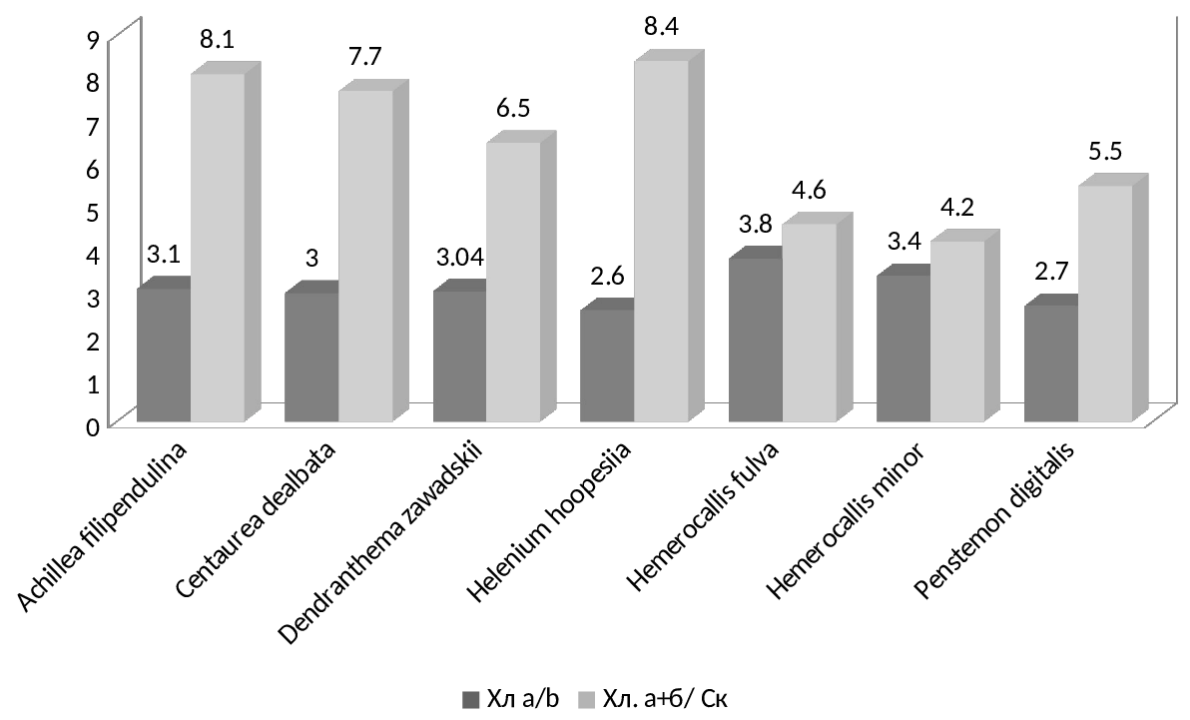

Рис. Соотношение хлорофилл $a /$ хлорофилл $b$ и хлорофилла $a+b /$ каротиноиды в листьях травянистых растений из коллекции ботанического сада СурГУ, мг/г.

Высокая величина соотношения хлорофиллы/каротиноиды у Achillea filipendulina (8,1 мг/г), Centaurea dealbata (7,7 мг/г) с максимальным содержанием суммы хлорофиллов связана с образованием генеративных органов и цветением этих видов в период исследования.

Максимальное значение соотношения хлорофиллы/каротиноиды отмечено у Helenium hoopesiia $(8,4$ мг/г), что связанно с видовой специфичностью и особенностью метаболизма растений.

Следует отметить, что у представителей семейства Hemerocallidoideae содержание суммы хлорофиллов и показатель соотношения хлорофиллы/каротиноиды ниже, чем у других исследуемых видов. Это свидетельствует о воздействии стрессового фактора в период адаптации и снижении физиологического статуса растений.

Таким образом, период вегетации и цветения характеризуется максимальными показателями содержания хлорофилла (6,6-7,6 мг/г), каротиноидов (0,8-0,9 мг/г), соотношения хлорофиллы/каротиноиды (7,7-8,1 мг/г). Для периода адаптации Hemerocallis fulva и Hemerocallis minor характерны более низкие величины соотношений хлорофиллов $a$ и $b(3,4-3,8$ мг/г), хлорофиллы/каротиноиды $(4,2-4,6$ мг/г) по сравнению с другими опытными растениями.

В дальнейшем планируется продолжить исследования биохимической адаптации травянистых растений ботанического сада в условиях культуры.

Исследование выполнено при финансовой поддержке Департамента образования и молодежной политики Ханты-Мансийского автономного округа - Югры (приказ № 1281 от 25.08.17г.).

\section{ЛИТЕРАТУРА}

Ананьина B. М. Вопросы физиологии устойчивости растений // Сельскохозяйственная биология, 2003. - № 1.- C. $120-124$.

Барковский $\boldsymbol{E}$. В. Современные проблемы биохимии. Методы исследований / под ред. А. А. Чиркин. - Минск: Высш. шк., 2013. - 491 с.

Карпова E. A., Фершалова T. Д. Динамика содержания пигментов в листьях Begonia grandis Dryandersub sp. grandis при интродукции в Западной Сибири (г. Новосибирск) // Вестник Томского государственного университета. Биология, 2016. - № 1 (33). - С. 140-158.

Фомина T. И. Биологические особенности декоративных растений природной флоры в Западной Сибири. Новосибирск: Гео, 2012.-179 с.

Lichtenthaler H. K., Buschmann C. Chlorophylls and Carotenoids: Measurement and Characterization by UV-VIS Spectroscopy / In: Current Protocols in Food Analytical Chemistry. F4.3.1-F4.3.8. - N.Y.: John Wiley et Sons, 2001. 